\title{
In Search of a Sulphur Dioxide Environmental Kuznets Curve: A Bayesian Model Averaging Approach*
}

\author{
Jeffrey Begun \\ University of Washington \\ Theo S. Eicher \\ University of Washington
}

\begin{abstract}
The exact specification and motivation of the Environmental Kuznets Curve (EKC) is the subject of a vast literature in environmental economics. A remarkably diverse set of econometric approaches has been employed to support or reject a specific relationship between environmental quality and pollution. Nevertheless, methods employed to date have not addressed the issue of model uncertainty, given that a sizable number of competing theories exist that can explain the income/pollution relationship.

We introduce Bayesian Model Averaging to the EKC analysis to examine a) whether a sulphur dioxide EKC exists, and if so, b) which income/pollution specification is most strongly supported by the data. We find only weak support for an EKC, which disappears altogether when we address oversampling issues in the data. In contrast, our results highlight the relative importance of political economy and site-specific variables in explaining pollution outcomes. Trade is also shown to play an important indirect role. It moderates the influence of the composition effect on pollution. Our findings run contrary to the deterministic view of the income/pollution relationship that is persistent in the literature.
\end{abstract}

*We thank Werner Antweiler and Bill Harbaugh for sharing their data and Chris Papageorgiou for comments. 


\section{Introduction}

A vast empirical literature has sought to establish a robust relationship between economic development and environmental quality. Grossman and Krueger (1995) and Selden and Song (1994) examined the relationship and documented an inverted U-shaped curve between income and pollution that is similar to the inverted U-shaped relationship between income and inequality first proposed by Kuznets (1955). The early data seemed to support an "environmental Kuznets curve" (EKC) where initial phases of development are associated with increasing pollution while richer nations experience improvements in their environmental quality.

Subsequently, however, a large number of authors have failed to confirm the EKC either in the original Grossman and Krueger dataset or in updated and expanded pollution datasets (see, e.g., Harbaugh et al., 2002, or Deacon and Norman, 2006). The conflicting empirical results have given rise to intense attempts either to formally model the EKC process (see e.g., Antweiler et al., 2001), or to add further control variables to reduced-form regressions to examine whether the EKC relationship can be resurrected and/or remain robust when the model is correctly specified (see, e.g., Panatayotou, 1997).

The EKC is a case study of extreme model uncertainty where the true model is unknown and several competing approaches exist to formalize the relationship between environmental quality and income. In light of such model uncertainty, inference procedures based on only one regression model overstate the precision of coefficient estimates since the uncertainty surrounding the validity of a theory has not been taken into account (see Doppelhofer, 2005). The problem is particularly prevalent in the EKC literature since a number of well-founded approaches exist and researchers face an abundance of possible candidate regressors.

Bayesian Model Averaging (BMA) allows inferences to be based on a number of competing models, each weighted by its quality. The procedure naturally delivers a posterior distribution for each candidate regressor, whose mean is a smoothed estimate derived from all relevant models. Hundreds of BMA papers have been published in the last decade as increases in computing power allow end users to trawl through thousands of models mechanically in attempts to address model uncertainty. In environmental economics, prominent examples of BMA applications include the modeling of population determinants for deer and fish in Farnsworth et al. (2006) and Fernandez, Ley and Steel (2002), respectively. To our knowledge, we are the first 
to apply Bayesian Model Averaging to resolve the model uncertainty surrounding the EKC relationship.

Our strategy is to group EKC approaches into two categories. First we examine reducedform approaches to the EKC, where many possible determinants of pollution are tested. Then we examine specific theories that have been proposed as the underlying determinants of an EKC, and scrutinize how strongly the data supports theory-based candidate regressors. Before we summarize our results, it is important to note that the updated $\mathrm{S}_{2}$ data that has been extended and cleaned of previous errors no longer exhibits the EKC relationship that Grossman and Krueger (1995) discovered (see, e.g., Harbaugh et al., 2002). Hence our results below can be seen as an effort to find robust evidence for an $\mathrm{EKC}$ in this dataset by eliminating possible omitted variable bias.

We find only limited evidence for an income/pollution relationship once we account for model uncertainty in the data. Instead, robust and strongly related regressors in both reducedform and theory-based approaches are those relating to political economy, site-specific effect,s and trade-induced composition effects. Societies that are more open in terms of political participation are shown to exhibit significantly lower air pollution.

The theory-based approach highlights that the exact theoretical specification of the trade effect on pollution matters. Following Antweiler et al. (2001), we show that the interaction between trade and capital intensity is of crucial importance to explain the evolution of $\mathrm{SO}_{2}$ concentrations across countries and time. We also show that the composition effect has a different impact on countries depending on their level of development. The greater the level of development - as proxied by the human capital augmented capital-labor ratio - the lower the implied concentrations for open economies. We also find support for pollution havens, since the negative coefficient implies that countries with low capital intensity and high trade orientations have higher pollution levels (see Birdsall and Wheeler, 1993).

It is important to note that the number of regressors that are robustly related to pollution in the BMA approach, as well as the best model identified by BMA, contains only a fraction of the 23 possible candidate regressors and only about one third of the 18 regressors suggested by the most comprehensive theoretical specification in Antweiler et al. (2001). This provides evidence that such a complex theory may not be necessary and alternative theories, such as the 
Green Solow model, should not be discarded simply because they rely on only a fraction of the regressors that Antweiler et al. (2001) introduced (see Taylor and Brock, 2003). Not only is the number of robustly related regressors in BMA smaller than previous approaches suggested, several are also not exclusively related to economic fundamentals.

Nevertheless, the best model suggested by BMA, which accounts for model uncertainty, has an R-squared of 0.242 at the most disaggregated level, which is twice as high as Antweiler et al.'s (2001) preferred full fixed-effects specification $\left(\mathrm{R}^{2}=0.15\right)$. Indeed, the best model identified in our preferred specification, which also addresses the severe oversampling issues in the data, features an R-squared of 0.514. This implies that the significance of the large number of regressors in previous theory-based and reduced-form regressions may be an artifact of an approach that did not take into account model uncertainty.

\section{2) The $\mathrm{SO}_{2} \mathrm{EKC}$}

\section{1) Data Considerations}

Perhaps the most salient EKC relationship in the literature is between air quality and development. ${ }^{1}$ In this paper we focus on median sulphur dioxide $\left(\mathrm{SO}_{2}\right)$ concentration data from the Global Environmental Monitoring System (GEMS) to search for an EKC. The data is updated, error-corrected and maintained by the EPA in its Aerometric Information Retrieval System (AIRS). ${ }^{2}$ The GEMS/AIRS data is perhaps the most widely used dataset to investigate the $\mathrm{EKC}$, with reported $\mathrm{SO}_{2}$ concentrations from stations in up to 44 countries from 1971 to 2006. ${ }^{3}$ However, most of the data since the early 1990s exists only for the United States.

Our income measure is real GDP per capita in constant 1996 dollars from the Penn World Tables 6.1 (Heston, Summers and Aten, 2002). In a later section when we compare results to Antweiler et al. (2001, subsequently referred to as ACT), we also use their GNP data as an income measure. We use concentration data, although emissions data is also widely available,

\footnotetext{
${ }^{1}$ Alternative measures have been used. Evidence for an EKC has been found for water quality (Grossman and Krueger, 1995), deforestation (Cropper and Griffith, 1994; Panayotou, 1995) and water withdrawal for agriculture (Rock, 1998; Goklany, 2002). Some researchers have found an EKC for carbon dioxide (Roberts and Grimes, 1997) though others have found that $\mathrm{CO}_{2}$ increases monotonically with income (Shafik and Bandyopadhyay, 1992).

${ }^{2}$ Our raw GEMS/AIRS data is identical to Antweiler, Copeland and Taylor (2001), who kindly shared their data that includes median concentrations.

${ }^{3}$ See, for example, Grossman and Krueger (1995), Panayotou (1997), Torras and Boyce (1998), Barrett and Graddy (2000), Harbaugh et al. (2002) and Deacon and Norman (2006).
} 
because it is the concentration of $\mathrm{SO}_{2}$ in the atmosphere that matters for the environmental impact.

The $\mathrm{SO}_{2}$ data is, however, highly unbalanced in two dimensions: location and time. Few countries report data over the entire time period, and many countries report pollution concentrations for less than a decade. Often entire years of data are missing between observations not only on the station level, but also on the city and country level. Even in countries with extensive locational coverage, such as the United States, the time series for each monitoring station is highly unbalanced.

The data are unbalanced in terms of location since a few countries are represented with large numbers of reporting stations, while many other nations feature only one. A full 38 percent of the original 2,555 station-level observations originate in the U.S. and Canada. The imbalance is exacerbated early and late in the sample as the U.S. supplies 69 percent of the data before 1974 and after 1993. Therefore we restrict our analysis to 1994-1993, which reduces the dataset by 219 mostly U.S. observations. The literature has largely been concerned with documenting the EKC (or the absence thereof) without acknowledging the fact that the dataset is so extremely unbalanced. In Section 2.2 we discuss measures to balance the sample, which require us to drop seven countries with a total of 128 observations because they lacked either $\mathrm{SO}_{2}$ or PWT 6.1 for at least two five-year periods. ${ }^{4}$ Finally, we had to drop Hong Kong (40 observations) because it lacked the Polity IV data described below, and Yugoslavia was dropped by ACT because it lacks human capital data. Figure 1 provides a breakdown of the 2168 observations by country of origin.

\subsection{The EKC in the Raw Income Pollution Data}

As mentioned in section 2.1, we employ the same GEMS dataset for income and sulphur dioxide pollution that has been used extensively in the previous literature. Starting with the very first paper by Grossman and Krueger (1991) and continuing on to perhaps the most prominent recent work on the income/pollution relationship by ACT, this dataset has been the cornerstone of EKC support. The first surprise for researchers using the newest version of GEMS, which has been purged of errors and extended to include updated data, is that it no longer provides evidence for

\footnotetext{
${ }^{4}$ These countries (and their number of observations) are Austria (2), Kenya (4), Switzerland (2), Ghana (3), Czech Republic (21), Poland (86) and Iraq (9). Iraq and Poland are excluded only when we use GDP measures. A complete description of the data used in this paper is provided in the appendix.
} 
the fundamental EKC relationship. Figure 2 plots the raw data for every station in every year that an observation is recorded. In addition, the figure traces the predicted values from the most fundamental regression that includes only $\log \mathrm{SO}_{2}$ concentrations as the dependent variable and real GDP per capita as a third-order polynomial. ${ }^{5}$ In Grossman and Krueger (1995), a similar plot was prominently inverted-U shaped.

Instead of an EKC, the updated GEMS data in Figure 2 shows a simple relationship between development and environmental quality that has $\mathrm{SO}_{2}$ concentrations gradually declining with income. The lack of an EKC in the raw $\mathrm{SO}_{2}$ data has previously been noticed by astute researchers who suggested that global data masks country-level phenomena. Deacon and Norman (2006) provide strong evidence that the country-level experience may in fact look very different from the global station-level data. Since technology, factor abundance and the political response to interest groups are also national concepts, we aggregate the data in search of an EKC at the individual country level. Figure 3 confirms Deacon and Norman's (2006) results by plotting country-level $\mathrm{SO}_{2}$ concentrations over time and showing that most countries' $\mathrm{SO}_{2}$ concentrations do not follow an EKC path. In fact, it is difficult to discern any country in Figure 3 that exhibits the single peak predicted by the EKC hypothesis. Indeed, Deacon and Norman (2006) show that diverse $\mathrm{SO}_{2}$-income relationships exist among countries; depending on the nation, rising income may be associated with rising, falling or stable $\mathrm{SO}_{2}$ concentrations.

The lack of an EKC at the station or individual country level might be an artifact of the extremely unbalanced time- and location-dimensions of the dataset. Since our main explanatory variable, real GDP per capita, is defined at the country level, oversampling in countries with multiple reporting stations may bias the station-level regressions severely. To balance the sample, we follow Selden and Song (1994) and take five-year averages that correct for much of the time and locational imbalances discussed in Section 2.1. In the averaged dataset, the U.S. prominence is reduced to 24 percent of the observations at the station-level. Therefore, averaging helps address our oversampling concerns, and in the country-level data the entire locational

\footnotetext{
${ }^{5}$ We employ fixed-effects regressions throughout. It has been argued that the random effects EKC cannot be estimated consistently (Mundlak, 1978; Hsiao, 1986; Stern, 2003). Since the very premise of the EKC is that specific local, regional or national characteristics are crucial, the random-effects approach suffers from inconsistency due to omitted variables. In addition, we have no desire to imply that a possible EKC in our data holds beyond the countries in this sample. Hence, we take the view that countries represented are not simply random draws from a larger EKC country/station population. An additional advantage of the fixed-effects approach is that it controls for many time-invariant, site-specific and country-specific factors.
} 
imbalance that leads to oversampling concerns is eliminated. Averaging data over five-year intervals is also common in the economic growth literature and allows us to address the error associated with business cycle fluctuations that are inherent in income data (see Barro, 1990). Nevertheless, we will continue to examine and report results for all three levels of aggregation.

Averaging across time and aggregating by country does not resolve the mystery of the missing EKC in the raw data, however. Plotting the station-level data and the predicted values obtained by the same method as in Figure 2, the country-level data in Figure 4 maintains the negative relationship between pollution and income. The monotonic decline is a bit surprising given past support for an EKC in the GEMS data (e.g., Shafik, 1994; Grossman and Krueger, 1995; Torras and Boyce, 1996; Panayotou, 1997). A careful study by Harbaugh, Levinson and Wilson (2002) with the revised GEMS/AIRS data, however, found evidence that sulphur dioxide concentrations may initially decline as income rises. In addition, Perman and Stern (2003), who use the same data and make adjustments for previous methodological and data problems with appropriate statistical techniques, also found no EKC evidence. Given the heterogeneity observed in Figure 3, and the results of Deacon and Norman (2006), our station-level results are not surprising.

\section{Model Uncertainty in the Income / Environment Relationship}

Two simple explanations can address the absence of an EKC in the raw data presented in Figures 2 and 4. Either the relationship does not exist, or the model is misspecified. By neglecting to include crucial covariates, the misspecification due to omitted variable bias may overwhelm the power of the GDP regressors. Perhaps in an effort to explore the latter line of reasoning, the literature features a remarkably diverse range of different model specifications to uncover evidence in favor of an EKC.

Below, we first focus on the most prominent reduced-form approaches that commonly include variables to sharpen the EKC model specification such as international trade, capital intensity, precipitation variation, temperature, population density, investment, education, institutions, and interaction terms. Instead of juxtaposing various versions of different researchers' preferred models as is standard in robustness analysis, we use an advanced model selection technique to address the model uncertainty inherent in the EKC literature. Bayesian Model Averaging (BMA) is the most sophisticated and theoretically grounded method to address 
model uncertainty. The next section provides a brief abstract of the BMA method and identifies how the procedure resolves EKC model uncertainty.

\subsection{Addressing Model Uncertainty in the Income / Environment Relationship}

The issue of model uncertainty in general has long been recognized as a major problem in economics. When inferences are based on one model alone, the ambiguity involved in model selection dilutes information about effect sizes and predictions since "part of the evidence is spent to specify the model" (Leamer, 1978, page 91). It is therefore not surprising that averaging over all models can be proven to provide better average predictive performance than just picking any single model (Madigan and Raftery, 1994).

The basic model averaging idea originated with Jeffreys (1961) and Leamer (1978), whose insights were developed and operationalized by Draper (1995) and Raftery (1995). BMA was first introduced to economics by Fernandez, Ley and Steel (2001), with an application to economic growth. Here we restrict ourselves to sketching the basic BMA structure before we discuss the results (for an extensive discussion of BMA see Hoeting, Madigan, Raftery and Volinsky, 1999). Environmental applications of BMA include (among many others) Farnsworth et al. (2006) and Fernandez, Ley and Steel (2002).

Consider $n$ independent replications from a linear regression model. The dependent variable ( $\mathrm{SO}_{2}$ pollution) in $n$ countries grouped in vector $\gamma$ is regressed on an intercept $\alpha$ and a number of explanatory variables chosen from a set of $k$ candidate regressors contained in a design matrix $Z$ of dimension $n \times k$. Assume that $r\left(l_{n}: Z\right)=k+1$, where $r($.$) indicates the$ rank of a matrix and $l_{n}$ is an $n$-dimensional vector of ones. Further define $\beta$ as the full $k$ dimensional vector of regression coefficients.

Now suppose that we have a $n \times k_{j}$ submatrix of variables in $Z$ denoted by $Z Z_{j}$. Then denote by $M_{j}$ the model with regressors grouped in $Z_{j}$, such that

$$
y=\alpha l_{n}+Z_{j} \beta_{j}+\sigma \varepsilon
$$

where $\beta_{j} \in \mathfrak{R}^{k_{j}} \quad\left(0 \leq k_{j} \leq k\right)$ groups regression coefficients corresponding to the submatrix $Z_{j}$, $\sigma \in \mathfrak{R}_{+}$is a scale parameter, and $\varepsilon$ is a random error term that follows an $n$-dimensional 
normal distribution with a zero mean and an identity covariance matrix. Exclusion of a regressor in a particular model implies that the corresponding element of $\beta$ is zero. Since we allow for any subset of variables in $Z$ to appear in each model, $M_{j}$, there exist $2^{k}$ possible sampling models.

Given this setup, BMA implies that the posterior probability of any given parameter of interest, $\Delta$, has a common interpretation across models. It is the weighted posterior distribution of $\Delta$ under each of the models, with weights given by the posterior model probabilities, or

$$
P_{\Delta \mid y}=\sum_{j=1}^{2^{k}} P_{\Delta \mid y, M_{j}} P\left(M_{j} \mid y\right) \text {. }
$$

That is, the marginal posterior probability of including a particular regressor is the weighted sum of the posterior probabilities of all models that contain the regressor. The posterior model probability for Model $M_{j}$ is given by

$$
P\left(M_{j} \mid y\right)=\frac{l_{y}\left(M_{j}\right) p_{j}}{\sum_{h=1}^{2^{k}} l_{y}\left(M_{h}\right) p_{h}}
$$

where $l_{y}\left(M_{j}\right)$, is the marginal likelihood of model $M_{j}$ given by

$$
l_{y}\left(M_{j}\right)=\int p\left(y \mid \alpha, \beta_{j}, \sigma, M_{j}\right) p(\alpha, \sigma) p\left(\beta_{j} \mid \alpha, \sigma, M_{j}\right) d \alpha d \beta_{j} d \sigma
$$

Note that $p\left(y \mid \alpha, \beta_{j}, \sigma, M_{j}\right)$ is the sampling model corresponding to equation (1), and $p(\alpha, \sigma)$ and $p\left(\beta_{j} \mid \alpha, \sigma, M_{j}\right)$ are the priors of the intercept and the regressors, respectively.

Thus, BMA does not rely on any individual model to generate inferences, but provides a posterior distribution for each estimate. BMA thus bases the inference on the weighted average of a selection of models. The weights themselves are given by a measure of the quality of each individual model relative to all other models. BMA therefore constitutes an intuitively attractive solution to model uncertainty as it considers all possible models and generates an average that is dominated by models which receive the greatest support from the data.

Despite its theoretical rigor and power of inference, BMA has not yet become part of the standard data analysis tool kit. This has been due to several early difficulties in implementing 
BMA. First, the number of terms in equation (1) can be enormous, rendering exhaustive summation infeasible. This problem has recently been addressed by an efficient search algorithm incorporated into the Raftery et al. (1997) "bic.reg" routine. ${ }^{6}$ The routine guarantees that the best model is found, while alternative samplers such as MC3 (Madigan et al., 1995) or the totally random coin flip sampler (Sala-i-Martin, Doppelhofer and Miller, 2003) do not provide such an efficient search.

Much more problematic for BMA has been the Bayesian requirement to specify prior distributions for all parameters in all competing models. An extensive discussion on the significance of priors in BMA is provided by Fernandez, Ley and Steel (2001) and in Eicher, Papageorgiou and Raftery (2006). In our application of BMA below, we utilize priors that are among the most conservative and diffuse Bayesian priors. The unit information prior employed below is so diffuse and uncontroversial that it can be derived from frequentist statistics. ${ }^{7}$

\section{Reduced-Form Approaches to the EKC}

Before we can employ BMA, we must motivate the various candidate regressors that are to be included alongside the GDP measures. A number of covariates have been introduced in the past to explain sulphur dioxide concentrations. These regressors can be grouped into five different categories: 1) site-specific controls, 2) political economy proxies, 3) production structure, 4) trade measures, and 5) technology proxies. We discuss each one in detail below.

Stations from 44 countries around the world report sulfur dioxide concentrations in the GEMS/AIRS data. A compelling argument can be made that any analysis of the incomepollution relationship must include regressors that control for site-specific factors. Examples of regional variations that may explain sulphur dioxide concentrations in the vicinity of a measuring station would be specific weather conditions (temperature and precipitation) or topographical features. Such regional differences affect nature's ability to cleanse sulphur dioxide from the atmosphere. While variables such as Temperature, Precipitation Variation, and topographic features are unlikely to be correlated with our economic variables, their inclusion is standard in the literature and meant to improve the accuracy of the estimates. Our site-specific controls are

\footnotetext{
${ }^{6}$ The software can be freely obtained from http://www.research.att.com/ volinsky/software/bicreg.

${ }^{7}$ The unit information prior is a multivariate normal prior with mean at the maximum likelihood estimate and variance equal to the expected information matrix for one observation (Kass and Wasserman, 1995). It can be thought of as a prior distribution that contains the same amount of information as a single, typical observation.
} 
obtained from ACT, who include average monthly temperatures for each reporting station to capture seasonal influences on the demand for fuels (and hence $\mathrm{SO}_{2}$ concentrations), and to account for the fact that higher temperatures allow $\mathrm{SO}_{2}$ to dissipate pollution more rapidly. We also include the variation in precipitation at each site from ACT since seasonally-concentrated rainfall reduces the region's ability to dissipate $\mathrm{SO}_{2}$ over the year. In addition, we add a dummy for nations who signed the 1985 Helsinki Protocol, which aimed to reduce sulphur emissions by at least 30 per cent. ${ }^{8}$

Before we turn to economic covariates, we must also control for common-to-world but nevertheless time-varying components. Such components are included to reflect secular changes in global awareness of environmental problems, innovations and diffusion of abatement technology, and the evolution of world prices. We follow the standard practice in the literature and seek to capture such common components with a linear time trend.

A number of studies have extended the pure EKC specification to include additional explanatory variables that may be tied to both pollution and economic development. Clearly income alone does not create pressure to improve environmental outcomes; the democratic fabric of a society that allows political participation and threatens consequences to polluting dictators is also seen as an important determinant. Hence the past literature introduced variables to account for the fact that more open and democratic societies may have different attitudes towards the environment. The conjecture is that for a given level of income, more open societies experience less pollution.

Many specific mechanisms for this to take place have been identified in the literature. Torras and Boyce (1998) posit that richer individuals gain "power" to demand better overall environmental quality. Likewise, Barrett and Graddy (2000) propose that wealthier citizens demand an increase in the non-material aspects of their standard of living. The degree to which policy responds to such desires is closely linked to the ability of individuals to assemble, organize and voice their concerns. In the same vain, Panatayotou (1997) provides evidence that strong property rights "flatten" the EKC by generating less pollution for any given income level.

\footnotetext{
${ }^{8}$ Much of the previous research, starting with Grossman and Krueger (1993, 1995), also includes site-geography variables such as proximity to oceans or deserts. Our fixed-effects regressions account for these implicitly.
} 
Several different measures of political rights and civil liberties have been used in the literature. Some authors have employed the Freedom House indices (e.g., Shafik and Bandyopadhyay, 1992; Torras and Boyce, 1998; Barrett and Graddy, 2000) while others such as Panayotou (1997) use "Respect/Enforcement of Contracts" from Knack and Keefer (1995). More recently Harbaugh et al. (2002) use an index of democratization from the Jaggers and Gurr (1995) Polity III dataset. Alternatively, Leitão (2006) introduces measures of corruption to examine how diversion activities may affect an EKC. The institutions and growth literature has since established the use of the "Constraint on Executive" variable from the updated Marshall and Jaggers (2003) Polity IV database as perhaps the best measure to capture the above mentioned effects. Acemoglu et al. (2001) have shown convincingly that the degree of constraint on the executive is a fundamental determinant of all political rights. We thus choose this measure as our political rights proxy. ${ }^{9}$

International trade has also been associated with the EKC relationship. Taylor and Brock (2004) survey the literature, highlighting an early contention by Arrow et al. (1995) and Stern et al. (1996) that an EKC might be partly or largely due to trade and its implied global distribution of polluting industries. Following the Heckscher-Ohlin model, the authors hypothesized that free trade allows developing countries to specialize in goods that are intensive in their relatively abundant factors: labor and natural resources. Developed countries, in turn, are likely to specialize in human capital and capital intensive goods. Following ACT, we use trade volume (exports plus imports) as a percent of GDP as our measure of openness to trade.

In contrast, Shafik and Bandyopadhyay (1992) point out that trade might exert two contrasting influences on developing countries. First, there exists the above effect where developing countries have an environmental comparative advantage due to low environmental protection costs, which leads to the intense manufacture and export of pollution-intensive goods. On the other hand, increased openness may lead to increased competition, which could cause more investment in efficient and cleaner technologies that meet the environmental standards of developed nations. To control for potentially opposing forces, we follow Harbaugh et al. (2002) and include not only trade, but also a measure of investment in our analysis. To the extent that a portion of investment leads to cleaner manufacturing processes, including investment should

\footnotetext{
${ }^{9}$ Note that the literature has clearly established the absence of a direct democracy/income relationship (Acemoglu et al., 2005). Hence we do not interpret our political economy measure as a proxy for income.
} 
help control for the role of technological change in explaining the EKC. Alternatively, tradeinduced dynamic comparative advantage has also been closely tied to the composition of output at different stages of development. This composition effect was proxied by Panayotou et al. (2000) with a capital intensity variable. Here we use an improved version of the capital intensity proxy from ACT who introduced a human capital adjusted capital-labor ratio.

Since a key hypothesis central to the EKC is that political pressure builds as richer agents demand greater environmental quality, education is also seen as a major factor in the pollution/development relationship. Torras and Boyce (1998) include adult literacy rates in their search for the EKC, noting that literacy allows greater informational access and a more even distribution of power within society. Our measure of education is years of education from Barro and Lee (2000). Years of education should be a better proxy for access to information since basic literacy only implies knowledge of rudimentary reading and writing skills. We use average years of education over the prior three years to account for the fact that it takes some time to translate educational achievement into environmental activism.

Another important covariate often included in the literature is population density (Grossman and Krueger, 1995; Panayotou, 1997; Barrett and Grady, 2000; ACT; Harbaugh et al., 2002). Panayotou argues that population density may have an ambiguous effect since more dense areas can expect greater use of coal and non-commercial fuels, but densely populated countries may also be more concerned about lowering pollution concentrations. We follow Harbaugh et al. (2002) and include national population density in order to have a relatively accurate time-series measure of population density for both developed and developing countries.

\subsection{Reduced-Form BMA EKC Results}

In Tables 1-3 we report the results from our BMA analysis which includes all variables that have been motivated by reduced-forms as described in the previous section. The results in the tables are robust to specifications of GDP in logs, different GDP lag structures (up to 10-year averaged lags) and alternative "U-curve" specifications such as Anand and Kanbur's (1993) specifications based on inverse GDP. The tables report results at the station, city and country level (Tables 1, 2 and 3 respectively). As is common in the literature, we include GDP and lagged GDP with linear and non-linear terms (see Grossman and Krueger, 1995, for example). In contrast to simple fixed- and random-effects regressions where collinearity between GDP and 
lagged GDP variables might compromise the explanatory power of either variable, BMA averages across relevant models and thus potentially mitigates the effects of collinearity.

The first column of each table reports the posterior inclusion probability, $\mathrm{P}$, which indicates the probability that the coefficient estimate is different from zero. ${ }^{10} \mathrm{P} \neq 0$ is thus a measure of confidence of including a candidate regressor with non-zero coefficient in the true regression model. The posterior inclusion probability has the additional advantage that it is a scale-free probability measure of the relative importance of the variables, which can therefore be transparently applied for policy decisions and inference, in addition to the posterior mean and standard deviation. Jeffries (1961) and Raftery (1995) add the additional interpretational refinement that $\mathrm{P} \neq 0>50$ percent suggests that the data provides weak evidence that the regressor is included in the true model; $\mathrm{P} \neq 0>75$ percent implies positive evidence; $\mathrm{P} \neq 0>95$ percent provides strong evidence; and $\mathrm{P} \neq 0>99$ percent gives very strong evidence. Inclusion probabilities close to 100 percent signal that the particular regressor is included in almost all good models, and that it contributes prominently to explaining the dependent variable even in the presence of significant model uncertainty.

Overall, we find only limited support for income as a key driver of $\mathrm{SO}_{2}$ concentrations. Only the highly unbalanced datasets at the station and city level (Tables 1 and 2) report positive evidence of an EKC relationship between income and $\mathrm{SO}_{2}$ concentrations (the GDP data is in $\$ 10,000)$. Table 1 shows that lagged GDP has a much higher inclusion probability than current GDP, implying that contemporaneous economic activity is much less important in determining $\mathrm{SO}_{2}$ concentrations than the indirect effects of rising income over time that may proxy for changes in technology. Nevertheless, fundamental variables, not income, are the most relevant for explaining pollution levels. Precipitation Variation and Executive Constraints both have 100 percent inclusion probabilities, while the income polynomials range around 80 percent. We find that less variation in precipitation, increased temperatures, and greater constraints on the country's chief executive reduce sulphur dioxide concentrations. The only economic variable that registers as significant in the reduced-form station level results is Trade Intensity. Here the evidence is decisive that trade reduces pollution.

\footnotetext{
${ }^{10}$ In contrast to frequentist statistics, where one null and one alternative model is implied, BMA considers all possible models, hence simple t-values are not appropriate. Indeed, Raftery (1995) notes that the theory of t-values was developed for the comparison of two nested models and in a typical structural equation model application, such as the EKC, there may be many substantively meaningful models (many of them non-nested).
} 
The best single regression model selected by BMA at the station level has an $\mathrm{R}^{2}$ of 0.249 , containing all eight variables that exhibit at least weak evidence in terms of inclusion probabilities. The city-level results in Table 2 are just about identical to those at the station level except that the previously weakly significant temperature variable is no longer relevant. Although the best model at the city-level is based on fewer regressors and less observations, its $\mathrm{R}^{2}$ increases to 0.319 . We surmise that the improvement in explanatory power results from the fact that the aggregated dataset is less prone to oversampling.

The major change in the results occurs when we aggregate the data to the country level. Table 3 no longer provides evidence that income has an influence on pollution. None of the GDP variables matter, perhaps because oversampling has eliminated the location bias and the dataset is balanced in terms of its time dimension. Nevertheless, all other variables that have been shown to be robustly related to pollution remain strongly significant and their posterior means are surprisingly stable. Political freedom, Trade, and local weather variations explain a large part of the pollution variability. Interestingly, at the country level, Education and technology (proxied by the Year variable) now have high inclusion probabilities, providing strong evidence that these candidate regressors belong to the true model. As we aggregate from the station to the city and finally to the country level, the $\mathrm{R}^{2}$ of the best model systematically increases (although the number of observations drops from 623 to 109 ). While the $\mathrm{R}^{2}$ is only 0.249 for the best model with station-level data, it rises to 0.475 at the country level.

In summary, after sorting through a wide range of models that have been proposed as reduced-form approaches to the $\mathrm{EKC}$, including all permutations on these models, BMA returns strong evidence that trade, political economy and site-specific factors are the main determinants of sulphur dioxide pollution. In all of the BMA analyses these variables are included with the expected sign. There is some evidence that $\mathrm{SO}_{2}$ concentrations are influenced by past income at the station and city levels, but this influence vanishes once we correct for oversampling. So far we have simply included variables without any specific theoretical support as to the overall model structure. In the next section we investigate if theory-specified functional forms and interactions may indeed lead to a specification that provides support for an EKC relationship.

\section{Theory-Motivated EKC Regressors}


Second-generation EKC models include not only variables motivated by heuristic, reduced-forms, but also fully specified models that yield precise, testable EKC implications and relationships. The essential features of the models include the determinants of scale, composition, and technique effects outlined by Panayotou (1997) and discussed in extensive detail by Taylor and Brock (2004). Prominent theoretical precursors that have led to the state of the art, fully specified, open-economy EKC model in ACT are Stokey (1998) (endogenous abatement), Bovenberg and Smulders (1995) and Aghion and Howitt (1998) (endogenous growth/technique), and Jones and Manuelli (2001) (endogenous policy). We direct the interested reader to the excellent Taylor and Brock survey and address only cornerstones of the theoretical EKC models that are relevant to empirical investigation.

All models that examine the development/pollution relationship make implicit assumptions regarding the strength of three different (and potentially offsetting) effects. First, development causes a positive scale effect since increased output per unit of capital leads to increased pollution. To account for the scale effect we follow ACT and employ a measure of city-level economic intensity (national GDP per capita times city population density). It is generally held that in rapidly growing middle-income countries pollution due to the scale effect might be the dominant EKC force (Perman and Stern 2003).

Second, a technique effect diminishes the scale effect as technological progress permits a lowering of emissions per unit of output. Lagged per capita income is used to proxy for the technique effect since countries with higher incomes in the past should be able to afford better technology today (see ACT). Diffusion of technology itself motivates the idea that time-related effects reduce environmental impacts in countries at all levels of development (Aghion and Howitt, 1998, Perman and Stern, 2003). These effects are usually proxied with a year dummy.

To isolate either the scale or technique effect, we must control for changes in the composition of output. A change in output composition can mitigate the scale effect further if the share of less pollution-intensive industries rises as income increases. This occurs when development and human capital accumulation generate shifts toward cleaner industries (services or information technology) and an ensuing change in the composition of output that then reduces environmental degradation (Panayotou, 1993). A specific model was first presented by Copeland and Taylor (2003), who showed that the reliance on capital accumulation in early stages of 
development, as opposed to human capital accumulation in later stages, can also generate an EKC. We capture the composition effect by controlling for differences in the capital-labor ratio that is adjusted for human capital, following ACT. In the absence of such controls, the pollutionincome relationship is a mixture of scale, composition, and technique effects, which is hard to interpret.

In addition to a simple income/output-induced composition effect, ACT also take into account a trade-induced composition effect. As discussed in the reduced-form literature, the effect of trade on pollution can be ambiguous. In ACT the trade-induced composition effect depends on the country's comparative advantage, which in turn is determined by income per capita and capital abundance. In moving from theory to practice, ACT suggest interacting the trade measure with determinants of comparative advantage (the capital-labor ratio and income per capita). Since comparative advantage is a relative concept, these are measured relative to the corresponding world averages. Since theory cannot identify a turning point (at what level of endowment trade causes a switch from exporting to importing pollution-intensive products), we adopt the flexible approach of ACT by estimating interactions with different functional forms.

To allow BMA to replicate the ACT results, we include a site-specific dummy for communist regimes which we interact with income per capita. This allows for a unique pollution-income dynamic in communist nations where political participation is extremely low. We can then test whether communist regimes are inherently disinterested in a public desire for a cleaner environment. Essentially we have already introduced a variable that proxies for the political economy effects with Executive Constraints, but BMA is exactly the appropriate statistical framework to elicit which one (if any) of these proxies influences pollution.

It is important to note that theory does not necessarily imply such an elaborate structure. As mentioned in the introduction, Taylor and Brock (2004) meticulously outline that the EKC is compatible with many different underlying mechanisms and theories. The simplest of all is perhaps the environment augmented "Green Solow model" where pollution policy remains unchanged throughout the development process and where transitional dynamics alone suffice to generate an EKC. The Green Solow model exhibits no composition effects, no changes in pollution abatement, no evolution of the political process and no international trade. Hence the Green Solow model is compatible with no change in trade or pollution policy as the country 
experiences positive growth. BMA is the natural statistical tool to examine the validity of the competing theories, and to address the inherent model uncertainty.

\subsection{Theory-Based BMA EKC Results}

The results in Table 4 contain theory-based candidate regressors (e.g., scale, composition, and technique effects) as well as proxies motivated by empirical implementations of reducedform hypotheses. Given that ACT's approach represents the most extensive, theory-based empirical implementation of the EKC hypothesis, we choose their results as a benchmark. ${ }^{11}$ It is comforting to see that the BMA results share a number of similarities with ACT. On the other hand, BMA also produces a number of surprises.

Different levels of aggregation (and hence different degrees of oversampling) generate remarkably stable outcomes in terms of posterior inclusion probabilities and posterior means. Table 4 shows that BMA identifies between four (city-level) and seven (country-level) candidate regressors with weak to decisive evidence of a non-zero impact on pollution. Common across all levels of aggregation is that there exists no evidence of an EKC. Instead, the prominence of sitespecific and political economy variables carries over from our structural results at all levels of aggregation. There is strong and decisive evidence that non-economic factors, such as Temperature, Precipitation, and Executive Constraints, affect pollution in the same fashion as in the reduced-form BMA Tables 1-3.

Of all variables that receive positive evidence in Table 4, only Executive Constraints does not appear in the theory-specified ACT model. Recall that ACT included the "Communist" variable to capture political economy effects, which was highly significant in their specification (although not in BMA). ${ }^{12}$ Executive Constraints thus remains highly significant not only in the reduced-form, but also in the structural analysis. This provides strong support for the Jones and Manuelli (2001) approach to pollution that emphasizes the political process, not income, as the driving force in the development/pollution relationship.

The major difference between the reduced-form specifications and the theory-based results is that Trade Intensity loses its significance entirely. While it does register as significant in the ACT model, BMA provides no evidence that Trade carries any explanatory power at the

\footnotetext{
${ }^{11}$ ACT do not report results for city or country level data.

12 The correlation between Communist/Income interaction used by ACT and Executive Constraints is -0.48 .
} 
station, city or country level. Nevertheless, the BMA results do suggest that Trade plays an important indirect role in determining pollution. The correct specification of the trade effect as outlined by the ACT theory is crucial. Here BMA reveals that the importance of Trade lies in its power to moderate the composition effect.

ACT find that Trade moderates the pure EKC effect as the trade/income interactions in their regression are highly significant. In the BMA approach, in contrast, this is income effect is confirmed only at the station level (ACT's level of aggregation). In the less unbalanced city- and country-level datasets, BMA indicates that Trade's sole role is to moderate the composition effect. The interaction between Trade and Capital Intensity shows that the composition effect has a different impact on countries depending on their level of development. The greater the level of development - as proxied by the human capital augmented capital-labor ratio - the lower the implied concentrations for open economies. The capital intensity variable has been included in the past to control for development-contingent shifts towards cleaner technologies; while it exhibited the same sign in ACT, it was statistically insignificant. The variable also provides support for pollution havens, since the negative coefficient implies that countries with low capital intensity and high trade orientations have higher pollution levels.

The second trade-related variable that receives strong support in BMA at all levels of aggregation is the interaction between Trade, GDP, and Capital Intensity. Interestingly, this variable is the one regressor that is estimated with just about the same coefficients and high level of significance in ACT as in BMA. The positive estimate throughout thus provides strong evidence that more human/physical-capital-intensive countries have higher sulphur dioxide concentrations, even after we control for trade and income effects. This is because the three-way interaction between Trade, GDP, and the Human Capital adjusted capital-labor ratio has a positive posterior mean. The relatively large role of the composition effect and the trade-based interactions suggests that countries do not follow a deterministic income-pollution path. Recall that Figure 3 highlights the variety of country-specific pollution paths as incomes rise.

In contrast to ACT, BMA does not find evidence for a pure composition effect as capital intensity alone cannot be shown to affect pollution. In addition, despite our efforts to control for possible contamination of the scale effect, BMA provides no evidence that scale effects matter at the station level (the scale effect was only mildly significant in ACT's work). Oversampling does 
influence the strength of the technique effect (proxied by Year), as BMA provides strong evidence that a technique effect reduces pollution at the country level. A similar pattern was observed in our reduced-form analysis, where the same variable gained explanatory power only at higher levels of aggregation. These findings are in line with Stern and Common (2001) and Stern (2002) who find evidence for the important role of negative time effects in explaining declining $\mathrm{SO}_{2}$ concentrations.

It is important to note that the best model chosen by BMA contains about a quarter of the 23 candidate regressors that have been motivated by the literature. At the station level, six highly significant regressors account for about twice the variation in the dependent variable $\left(\mathrm{R}^{2}=\right.$ $0.242)$ as the 18 regressors ( 13 significant) suggested by the ACT specification $\left(R^{2}=0.15\right)$. This could imply that a number of regressors identified by ACT may be significant only because the empirical strategy did not account for model uncertainty. The estimates at different levels of aggregation are surprisingly stable, however, and their $\mathrm{R}^{2}$ increases steadily from station, city, to country levels, from 0.24 to 0.34 to 0.51 , respectively. Also, the relevant regressors at the city and station level are just about identical, although the country-level results do feature two additional regressors to explain pollution (Year and Education). The coefficient on Education is counterintuitive just as in the reduced-form BMA results. It is supposed to proxy for the hypothesis that better-educated citizens demand better environmental quality. However, measures of education have been shown to be fragile in both growth regressions and in development accounting (see Krueger and Lindahl, 2001). Perhaps the same issues contaminate the effect of the regressors here.

\section{Conclusion}

This paper reexamines the evidence for an environmental Kuznets curve using the most recent EPA data on $\mathrm{SO}_{2}$ concentrations. The literature on the income-pollution relationship is vast and characterized by unusual model uncertainty as both the number of proposed theories and the range of possible candidate regressors is massive when it comes to empirical validation. We

apply a theoretically founded method to address model uncertainty. Bayesian Model Averaging examines all models, weighs them by their relative quality, and then generates a probability that a candidate regressor is related to the dependent variable. 
Our results are presented at three levels of aggregation. The station-level results are subject to severe oversampling as pollution from thousands of observations from local stations are linked to one and the same measure of income in a country. Hence we also aggregate the data to the city and country level. The results are remarkably robust. Political economy and sitespecific variables explain a large share of the observed pollution. International trade is also shown again and again to be robustly related to pollution. In our reduced-form analysis, trade is found to lower pollution. When the model is specified using full-fledged theory, we show that trade has no direct effect, but that it moderates the composition effect. As countries become richer and increase their physical and human capital, trade leads to cleaner environments. It unfortunately also implies that poor, labor-intensive, open economies experience increasing pollution levels.

Overall, we find only weak evidence for an EKC, which disappears when we address oversampling of the data or move to a theory-based analysis. There may be several reasons the EKC fails to hold up in our work. The foremost, perhaps, is that many countries in the time period covered by the GEMS/AIRS data may already be on the flat or the downward sloping portion of the EKC during the sample period. Smulders, Bretschger and Egli (2005) label these portions of the EKC the "alarm phase" and the "cleaning-up phase" that indicate government response to public concerns. Given that the rate of emissions reduction may also be based on governments reacting to their citizens' demands, it is not surprising that we find that policy variables such as Executive Constraints play a crucial role in determining pollution levels. 


\section{References}

Acemoglu, D., S. Johnson, and J. A. Robinson (2001), 'The colonial origins of comparative development: an empirical investigation', American Economic Review 91(5): 1369-1401.

Acemoglu, D., S. Johnson, J.A. Robinson, and P. Yared (2005), 'From education to democracy?' American Economic Review 95(2): 44-49.

Aghion, P. and P. Howitt (1998), 'Capital accumulation and innovation as complementary factors in long-run growth', Journal of Economic Growth 3: 111-130.

Anand, S. and S.M.R. Kanbur (1993), 'Inequality and development: a critique', Development Economics 41: 19-43.

Antweiler, W., B.R. Copeland, and M.S. Taylor (2001), 'Is free trade good for the environment?' American Economic Review 91: 877-908.

Arrow, K., B. Bolin, R. Costanza, P. Dasgupta, C. Folke, C.S. Holling, B-O Jansson, S. Levin, K-G Mäler. C. Perrings, and D. Pimentel (1995), 'Economic growth, carrying capacity, and the environment', Science 268: 520-521.

Barrett, S. and K. Graddy (2000), 'Freedom, growth, and the environment', Environment and Development Economics 5: 433-456.

Barro, R. J. (1990), 'Government spending in a simple model of endogenous growth', Journal of Political Economy 98: S103-S125.

Barro, R. J. and J-W Lee (2000), 'International data on educational attainment: updates and implications', CID Working Paper No. 42.

Birdsall, N. and D. Wheeler (1993), 'Trade policy and industrial pollution in Latin America: where are the pollution havens?' Journal of Environment and Development 2(1): 137-149.

Bovenberg, A.L. and S. Smulders (1995), 'Environmental quality and pollution-saving technological change in a two-sector endogenous growth model', Journal of Public Economics 57: 369-391.

Cole, M.A. (1999) 'Limits to growth, sustainable development and environmental Kuznets curves: an examination of the environmental impact of economic development', Sustainable Development 7(2): 87-97.

Copeland, B.R. and M.S. Taylor (2003), 'Trade and the Environment: Theory and Evidence', Princeton, N.J.: Princeton University Press, 2003.

Copeland, B.R. and M.S. Taylor (2004), 'Trade, growth, and the environment', Journal of Economic Literature 42(1): 7-71.

Cropper, M. and C. Griffiths (1994), 'The interaction of population growth and environmental quality', American Economic Review 84: 250-254.

De Bruyn, S.M., J.C.J.M. van den Bergh, and J.B. Opschoor (1998), 'Economic growth and emissions: reconsidering the empirical basis of environmental Kuznets curves', Ecological Economics 25: 161-175. 
Deacon, R.T. and C.S. Norman (2006), 'Does the environmental Kuznets curve describe how individual countries behave?' Land Economics 82: 291-315.

Doppelhofer, G. (2005), 'Model Averaging', in L. Blume and S. Durlauf. (eds.), The New Palgrave Dictionary of Economics, 2nd Edition, London: Palgrave Macmillan, forthcoming.

Draper, D. (1995), 'Assessment and propagation of model uncertainty (with discussion)', Journal of the Royal Statistical Society, Series B 57(1): 45-97.

Eicher, T.S., C. Papageorgiou, and A.E. Raftery (2006), 'Bayesian model averaging in economics', Working Paper.

Farnsworth, M.L., J. A. Hoeting, N. T. Hobbs, and M. W. Miller (2006), 'Linking chronic wasting disease to mule deer movement scales: a hierarchical Bayesian approach', Ecological Applications 16(3): 1026-1036.

Fernández, C., E. Ley, and M.F.J. Steel (2001), 'Model uncertainty in cross-country growth regressions', Journal of Applied Econometrics 16(5): 563-576.

Fernández, C., E. Ley, and M.F.J. Steel (2002), 'Bayesian modeling of catch in a north-west Atlantic fishery', Journal of the Royal Statistical Society: Series C 51: 257-280.

Goklany, I. (2002), 'Comparing twentieth century trends in US and global agricultural water and land use', Water International 27(3): 321-329.

Grossman, G.M. and A.B. Krueger (1991), 'Environmental impacts of a North American free trade agreement', NBER Working Paper 3914.

Grossman, G.M. and A.B. Krueger (1993), 'Environmental impacts of a North American free trade agreement,' in P. M. Garber, (ed.), The U.S.-Mexico Free Trade Agreement, Cambridge, MA: MIT Press, pp. 13-56.

Grossman, G. M. and A.B. Krueger (1995), 'Economic growth and the environment', Quarterly Journal of Economics 110(2): 353-377.

Harbaugh, W. T., A. Levinson, and D.M. Wilson (2002), 'Reexamining the empirical evidence for an environmental Kuznets curve', Review of Economics and Statistics 83: 541-551.

Heston, A., R. Summers, and B. Aten (2002), Penn World Table Version 6.1, Center for International Comparisons at the University of Pennsylvania (CICUP), [Computer File], URL: http://pwt.econ.upenn.edu/php_site/pwt_index.php.

Hoeting, J. A., D. Madigan, A. E. Raftery, and C.T. Volinsky (1999), 'Bayesian model averaging: a tutorial', Statistical Science 14: 382-417.

Hsiao, C. (1986), Analysis of Panel Data, Econometric Society Monographs No. 11, Cambridge: Cambridge University Press.

Jaggers, K. and T. R. Gurr (1995), 'Polity III: regime change and political authority, 1800-1994', [Computer File], URL: http://privatewww.essex.ac.uk/ ksg/Polity.html.

Jeffreys, H. (1961), Theory of Probability ( $3^{\text {rd }}$ Edition), Oxford: The Clarendon Press.

Jones, L.E. and R.E. Manuelli (2001), 'Endogenous policy choice: the case of pollution and growth', Review of Economic Dynamics 4(2): 369-405. 
Kass, R.E. and L. Wasserman (1995), 'A reference Bayesian test for nested hypotheses and its relationship to the Schwartz criterion', Journal of the American Statistical Association 90: 928-934.

Krueger, A. B. and M. Lindahl (2001), 'Education for growth: why and for whom?' Journal of Economic Literature 39(4): 1101-1136.

Kuznets, S. (1955), 'Economic growth and income inequality', American Economic Review 45(1): 1-28.

Leamer, E. (1978), Specification Searches, New York: Wiley.

Leitão, A. (2006), 'Corruption and the environmental Kuznets curve: empirical evidence for sulfur', Universidade Católica Portuguesa, Working Paper.

Madigan, D. and A. E. Raftery (1994), 'Model selection and accounting for model uncertainty in graphical models using Occam's Window', Journal of the American Statistical Association 89: $1535-1546$.

Madigan, D., J. York, and D. Allard (1995), 'Bayesian graphical models for discrete data', International Statistical Review 63(2): 199-214.

Marshall, M. G. and K. Jaggers (2003), Polity IV Project: Political Regime Characteristics and Transitions, 1800-2003, [Computer File], URL: http://www.cidcm.umd.edu/inscr/polity/.

Mundlak, Y. (1978), 'On the pooling of time series and cross section data', Econometrica 46(1): 69-85.

Panayotou, T. (1995), 'Environmental degradation at different stages of economic development', in I. Ahmed and J.A. Doeleman (eds.), Beyond Rio: The Environmental Crisis and Sustainable Livelihoods in the Third World, London: Macmillan, pp. 13-36.

Panayotou, T. (1997), 'Demystifying the environmental Kuznets curve: turning a black box into a policy tool', Environment and Development Economics 2: 465-484.

Panayotou, T., A. Peterson, and J. Sachs (2000), 'Is the environmental Kuznets curve driven by structural change? What extended time series may imply for developing countries', CAER II Discussion Paper 80.

Perman, R. and D. I. Stern (2003), 'Evidence from panel unit root and cointegration tests that the environmental Kuznets curve does not exist', Australian Journal of Agricultural and Resource Economics 47: 325-347.

Raftery, A.E. (1995), 'Bayesian model selection in social research (with discussion)', Sociological Methodology 25: 111-196.

Raftery, A.E., D. Madigan, and J.A. Hoeting (1997), 'Bayesian model averaging for linear regression models', Journal of the American Statistical Association 92: 179-191.

Roberts, J. and P. Grimes (1997), 'Carbon intensity and economic development 1962-91: a brief exploration of the environmental Kuznets curve', World Development 25: 191-198.

Rock, M.T. (1998), 'Freshwater use, freshwater scarcity, and socioeconomic development', Journal of Environment and Development 7: 278-301. 
Sala-i-Martin, X., G. Doppelhoffer, and R. Miller (2004), 'Determinants of long-term growth: a Bayesian averages of classical estimates (BACE) approach', American Economic Review 94(4): 813-835.

Selden, T.M. and D. Song (1994), 'Environmental quality and development: Is there a Kuznets curve for air pollution?' Journal of Environmental Economics and Environmental Management 27: 147-162.

Shafik, N. (1994), 'Economic development and environmental quality: an econometric analysis', Oxford Economic Papers 46: 757-773.

Shafik, N. and S. Bandyopadhyay (1992), 'Economic growth and environmental quality', World Bank Policy Research Working Paper WPS 904.

Smith, S.J., R. Andres, E. Conception, and J. Lurz (2004), 'Historical sulfur dioxide emissions 1850-2000: methods and results', PNNL Research Report, Joint Climate Change Research Institute, College Park.

Smulders, S., L. Bretschger, and H. Egli (2005), 'Economic growth and the diffusion of clean technologies: explaining environmental Kuznets curves', Economics Working Paper Series, Working Paper 05/42, WIF - Institute of Economic Research.

Stern, D.I. (2002), 'Explaining changes in global sulfur emissions: an econometric decomposition approach, Ecological Economics 42: 201-220.

Stern, D.I. (2004), 'The rise and fall of the environmental Kuznets curve', World Development 32(8): 1419-1439.

Stern, D.I. and M.S. Common (2001), 'Is there an environmental Kuznets curve for sulfur?' Journal of Environmental Economics and Management 41(2): 162-178.

Stern, D.I., M.S. Common, and E.B. Barbier (1996), 'Economic growth and environmental degradation: the environmental Kuznets curve and sustainable development', World Development 24(7): 1151-1160.

Stokey, N. L. (1998), 'Are there limits to growth?' International Economic Review 39: 1-31.

Taylor, M.S. and W. Brock (2004), 'Economic growth and the environment: a review of theory and empirics', Department of Economics Discussion Paper 2004-14, University of Calgary.

Torras, M. and J. Boyce (1998), 'Income, inequality, and pollution: a reassessment of the environmental Kuznets curve', Ecological Economics 25: 147-160. 


\section{APPENDIX}

Table A-1: Summary Statistics

\begin{tabular}{|c|c|c|c|c|c|}
\hline Variable & \# of Observations & Mean & S.D. & Min. & Max. \\
\hline Log of median $\mathrm{SO}_{2}$ & 653 & -4.883 & 1.052 & -6.908 & -2.181 \\
\hline GDP & 623 & 1.328 & 0.848 & 0.108 & 2.673 \\
\hline GDP $_{t-3}$ & 623 & 1.279 & 0.819 & 0.104 & 2.626 \\
\hline City-GDP/ $/ \mathbf{k m}^{2}$ & 653 & 6.666 & 8.061 & 0.103 & 57.565 \\
\hline $\mathbf{G N P}_{t-3}$ & 653 & 1.236 & 0.803 & 0.112 & 2.635 \\
\hline Executive Constraints & 653 & 5.689 & 2.003 & 1.000 & 7.000 \\
\hline Investment & 653 & 22.074 & 5.613 & 4.300 & 41.200 \\
\hline Trade & 653 & 0.404 & 0.264 & 0.129 & 1.484 \\
\hline Capital intensity $\left(H^{*} K / L\right)$ & 653 & 5.406 & 2.613 & 1.221 & 16.974 \\
\hline National Population Density & 653 & 0.236 & 0.265 & 0.005 & 1.187 \\
\hline Education $_{t-3}$ & 653 & 7.758 & 3.041 & 1.222 & 11.806 \\
\hline Communist * GNP & 653 & 0.038 & 0.125 & 0.000 & 0.716 \\
\hline Helsinki & 653 & 0.031 & 0.153 & 0.000 & 1.000 \\
\hline Temperature & 653 & 15.204 & 6.011 & 3.342 & 28.751 \\
\hline Precipitation Variation & 653 & 0.012 & 0.006 & 0.002 & 0.043 \\
\hline
\end{tabular}

Table A-2: Correlations

Log of median $\mathrm{SO}_{2}$
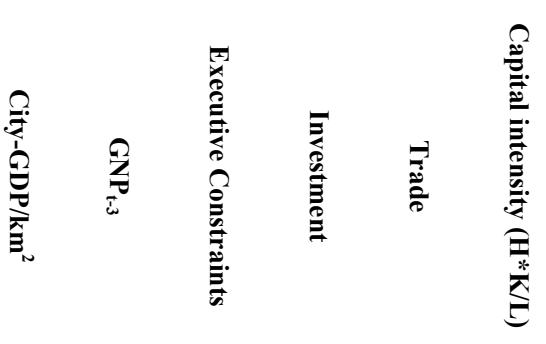

GDP (in 1996 \$10000)

\begin{tabular}{ccccccccccccc}
1.00 & & & & & & & & & & & \\
-0.21 & 1.00 & & & & & & & & & & \\
0.22 & 0.46 & 1.00 & & & & & & & & & \\
-0.18 & 0.97 & 0.43 & 1.00 & & & & & & & & \\
-0.28 & 0.67 & 0.27 & 0.65 & 1.00 & & & & & & & & \\
0.14 & 0.28 & 0.44 & 0.26 & 0.18 & 1.00 & & & & & & & \\
-0.03 & -0.06 & -0.20 & -0.09 & 0.09 & 0.15 & 1.00 & & & & & & \\
0.04 & 0.55 & 0.28 & 0.53 & 0.38 & 0.45 & 0.23 & 1.00 & & & & & \\
0.30 & -0.24 & 0.28 & -0.28 & 0.00 & 0.26 & 0.25 & -0.03 & 1.00 & & & & \\
-0.27 & 0.92 & 0.34 & 0.91 & 0.62 & 0.26 & -0.03 & 0.36 & -0.25 & 1.00 & & & \\
0.16 & -0.45 & -0.20 & -0.45 & -0.48 & 0.03 & -0.21 & -0.46 & 0.08 & -0.29 & 1.00 & & \\
-0.11 & 0.18 & 0.04 & 0.17 & 0.13 & 0.15 & 0.16 & 0.21 & -0.09 & 0.18 & -0.07 & 1.00 & \\
-0.16 & -0.47 & -0.17 & -0.49 & -0.30 & -0.31 & -0.23 & -0.43 & 0.13 & -0.49 & -0.04 & -0.25 & 1.00 \\
-0.02 & -0.57 & -0.31 & -0.57 & -0.36 & -0.42 & -0.10 & -0.52 & 0.18 & -0.53 & 0.17 & -0.21 & 0.44 \\
\hline & & & & & & & & & & & \\
\hline
\end{tabular}




\section{Figure 1 \\ Distribution of $\mathrm{SO}_{2} /$ Observations in GEMS/AIRS Data \\ 1974-1993}

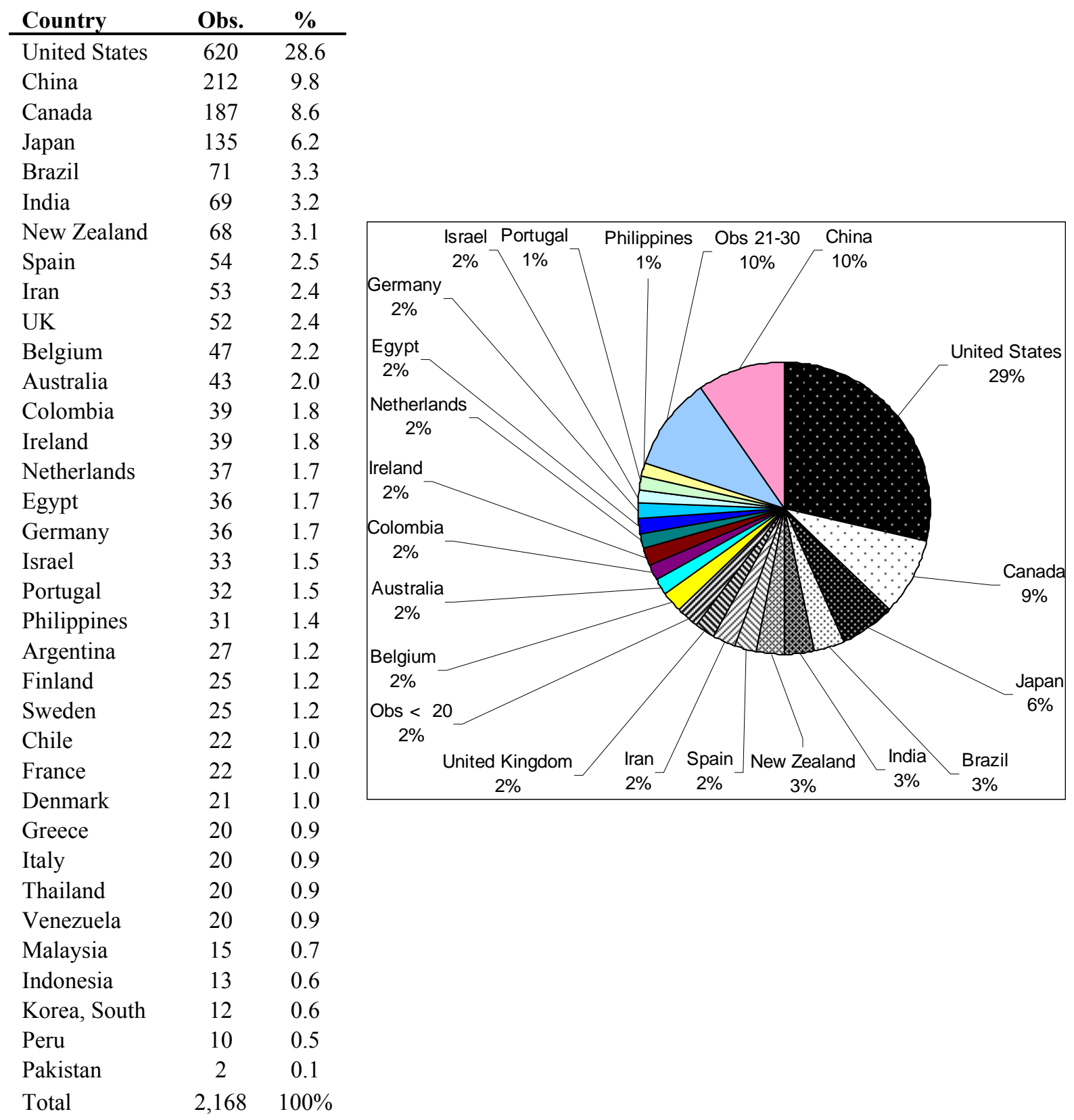

Source: US-EPA maintained GEMS/AIRS dataset http://www.epa.gov/airs/aexec.html 
Figure 2

Relationship between Median $\mathrm{SO}_{2}$ Concentrations and Income (By Measuring Station) 1974-1993

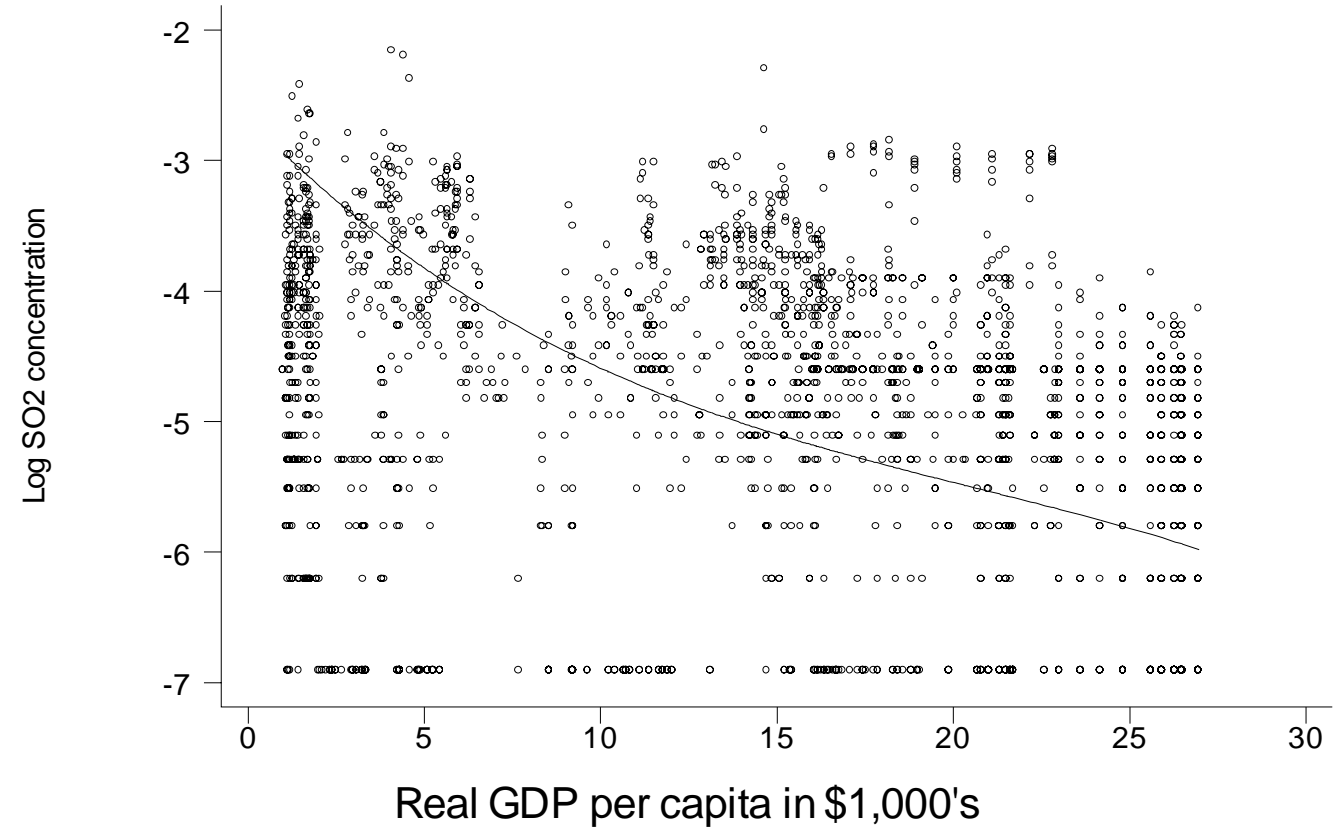

Source: US-EPA maintained GEMS/AIRS dataset http://www.epa.gov/airs/aexec.html

Note: Fitted values are fixed-effects regression $\log S_{2}=\alpha+\beta G D P+\delta G D P^{2}+\gamma G D P^{3}+\varepsilon$ 
Figure 3

Relationship between Median SO2 Concentrations and Income (by Country)
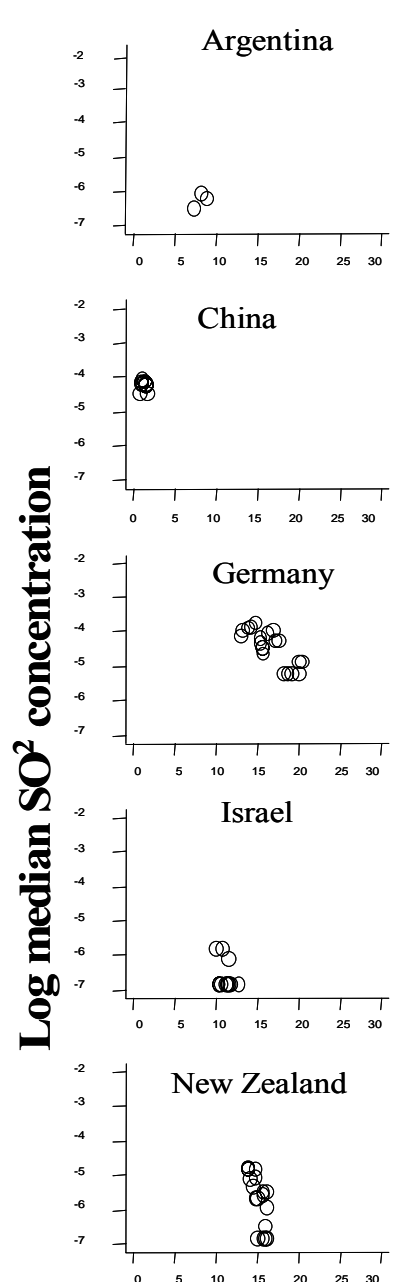

Sweden

8

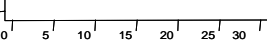

Australia
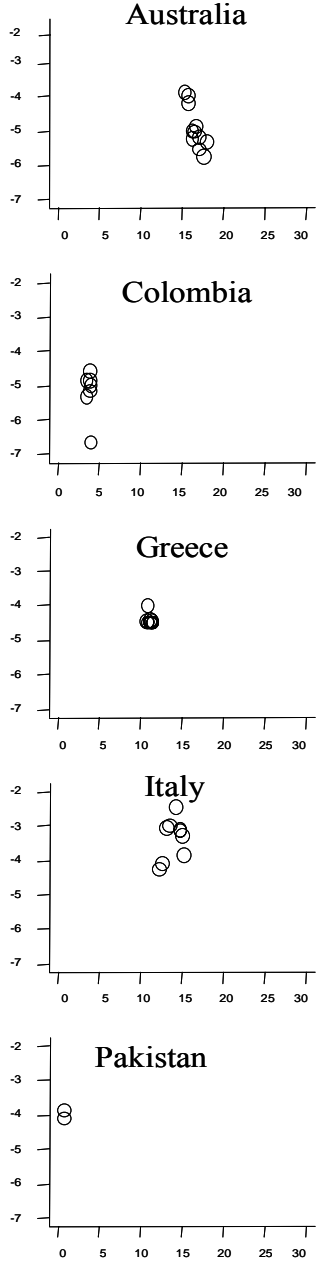

Thailand

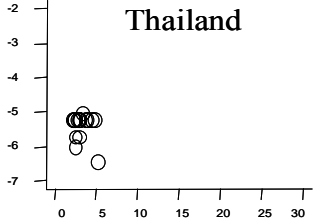

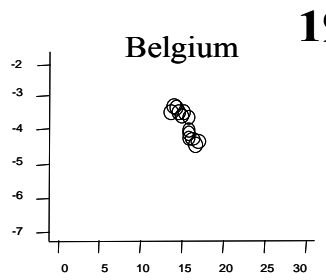

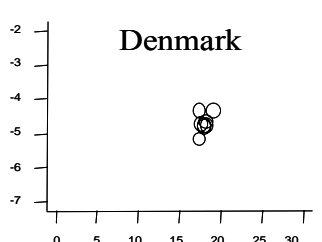

India

$-4-8$

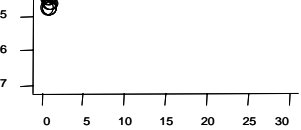

Japan
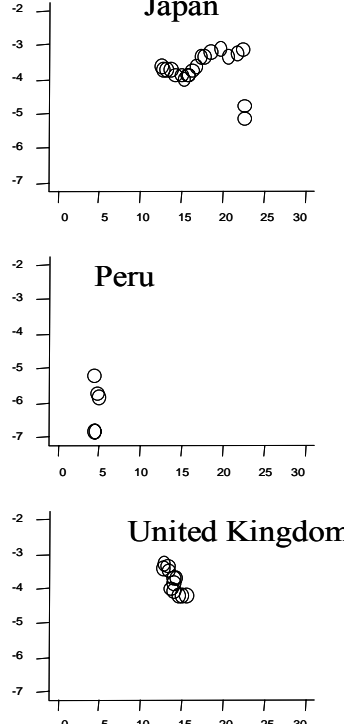
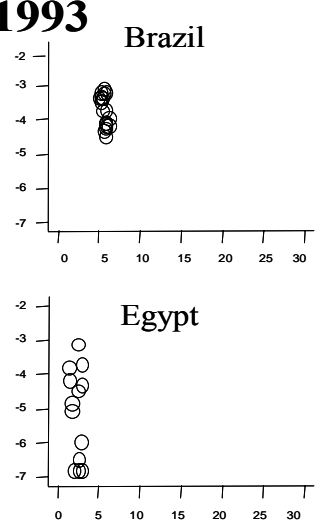

Indonesia

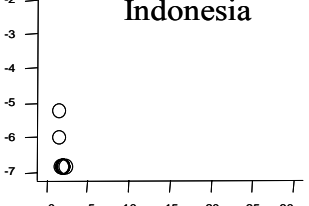

Korea, South
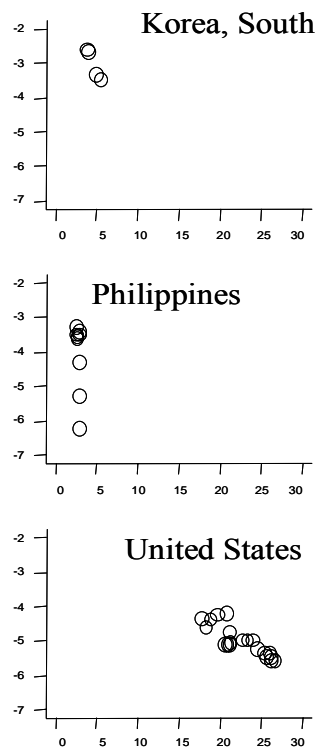

Real GDP per capita in $\$ \mathbf{1 , 0 0 0}$ 's
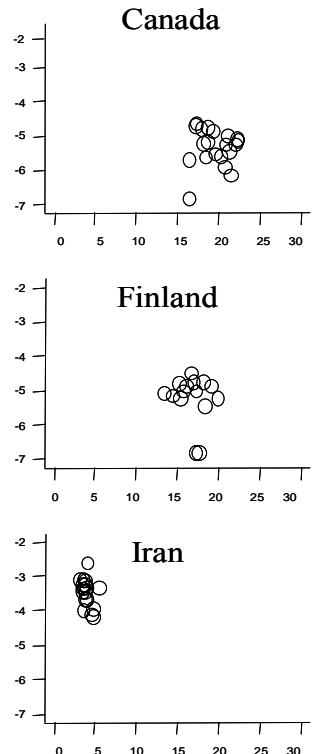

Malaysia
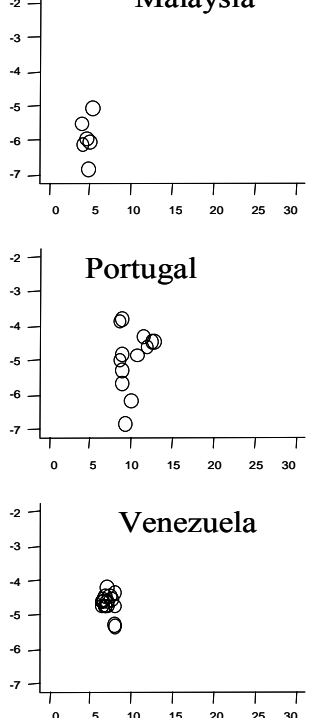
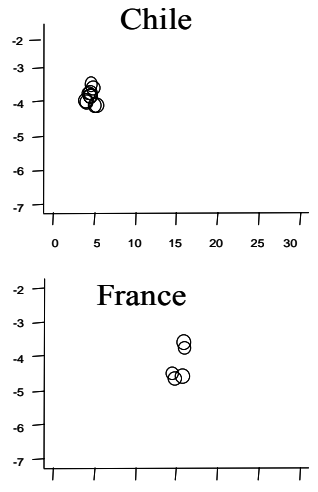

Ireland

(1)
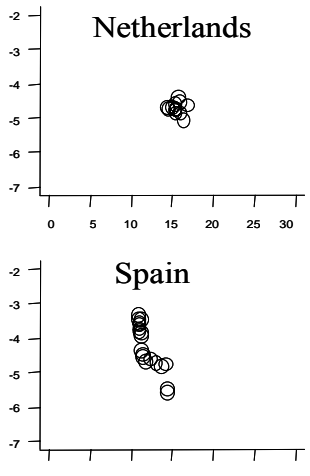

Source: US-EPA maintained GEMS/AIRS dataset http://www.epa.gov/airs/aexec.html. Note: Annual $\mathrm{SO}_{2}$ concentration averages, aggregated from station to country levels. 


\section{Figure 4}

Global Relationship between Median $\mathrm{SO}_{2}$ Concentrations and Income $1974-1993$

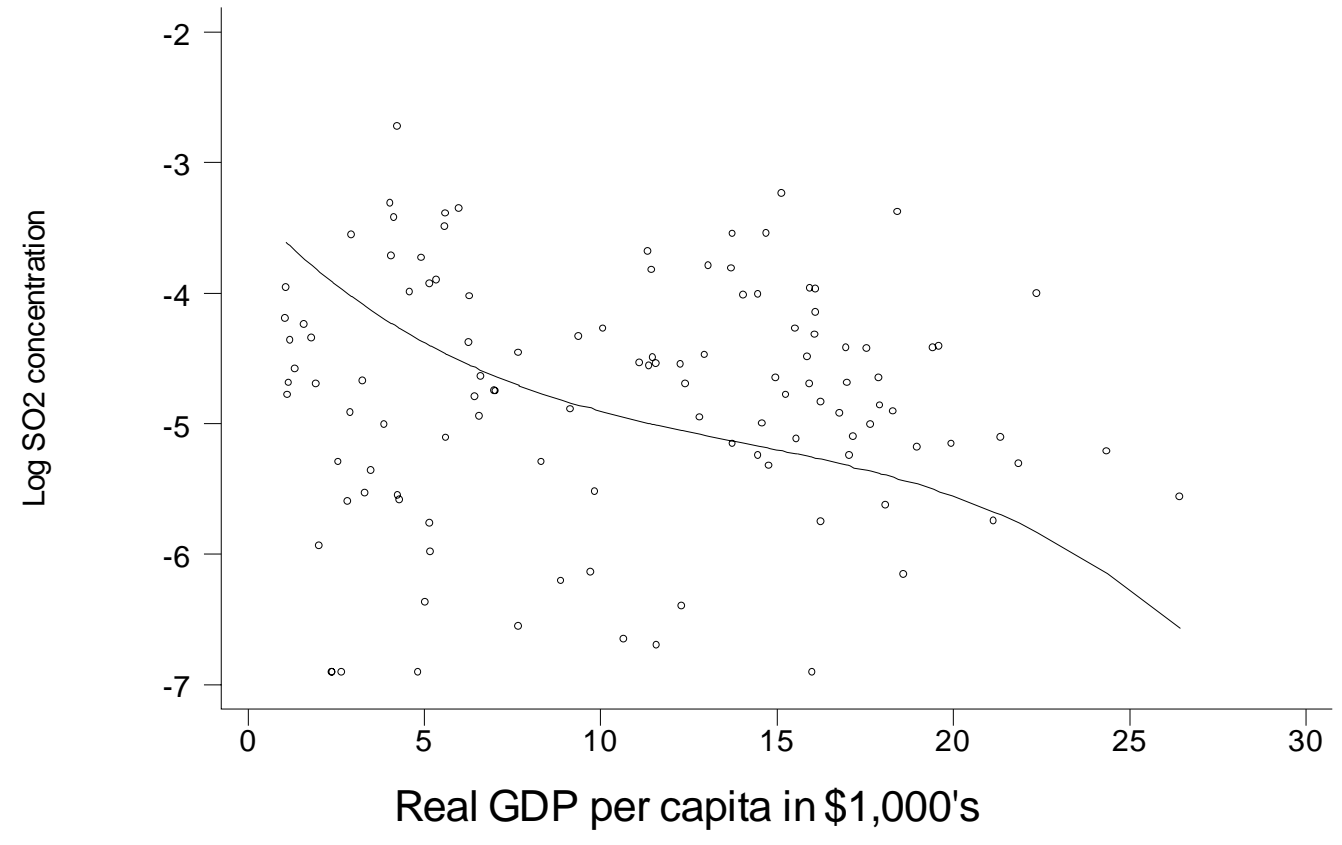

Source: US-EPA maintained GEMS/AIRS dataset http://www.epa.gov/airs/aexec.html Note: Five-year $\mathrm{SO}_{2}$ concentration averages, aggregated from the station to the country level. 


\section{Table 1}

\section{Reduced-Form BMA Results (By Station)}

\begin{tabular}{|c|c|c|c|}
\hline & \multicolumn{3}{|c|}{ Dependent Variable: Log median $\mathrm{SO}_{2}$ concentrations, 5-year averages } \\
\hline & $\mathbf{P} \neq \mathbf{0}$ & $\begin{array}{c}\text { Posterior Mean } \\
\text { (S.D.) }\end{array}$ & $\begin{array}{l}\text { Best Model Mean } \\
\text { (S.D.) }\end{array}$ \\
\hline Intercept & 100.0 & $\begin{array}{l}-2.6584 \\
(3.1423)\end{array}$ & $\begin{array}{c}-2.4109^{*} \\
(1.3776)\end{array}$ \\
\hline Precipitation Variation & 100.0 & $\begin{array}{l}45.2092 \\
(8.6828)\end{array}$ & $\begin{array}{l}45.1435 * * * \\
(10.6779)\end{array}$ \\
\hline Trade Intensity & 100.0 & $\begin{array}{l}-2.9292 \\
(0.4049)\end{array}$ & $\begin{array}{l}-2.9285 * * * \\
(0.4922)\end{array}$ \\
\hline Executive Constraints & 100.0 & $\begin{array}{l}-0.1932 \\
(0.0306)\end{array}$ & $\begin{array}{c}-0.1972 * * * \\
(0.0380)\end{array}$ \\
\hline$\left(G P_{t-3}\right)^{2}$ & 82.1 & $\begin{array}{l}-2.9432 \\
(1.5643)\end{array}$ & $\begin{array}{c}-3.4595 * * * \\
(0.9308)\end{array}$ \\
\hline $\mathbf{G D P}_{\mathrm{t}-3}$ & 81.9 & $\begin{array}{c}4.6092 \\
(2.4945)\end{array}$ & $\begin{array}{l}5.5128 * * * \\
(1.6123)\end{array}$ \\
\hline$\left(G P_{t-3}\right)^{3}$ & 81.9 & $\begin{array}{c}0.5505 \\
(0.2948)\end{array}$ & $\begin{array}{c}0.6416^{* * *} \\
(0.1790)\end{array}$ \\
\hline Temperature & 77.1 & $\begin{array}{l}-0.1365 \\
(0.0914)\end{array}$ & $\begin{array}{l}-0.1799^{* *} \\
(0.0785)\end{array}$ \\
\hline Investment & 46.3 & $\begin{array}{l}-0.0090 \\
(0.0111)\end{array}$ & . \\
\hline$(G D P)^{2}$ & 20.8 & $\begin{array}{l}-0.5119 \\
(1.1911)\end{array}$ & . \\
\hline$(G D P)^{3}$ & 20.8 & $\begin{array}{c}0.0886 \\
(0.2136)\end{array}$ & . \\
\hline GDP & 19.4 & $\begin{array}{c}0.8345 \\
(1.9899)\end{array}$ & . \\
\hline Capital Intensity, $H^{*} \mathrm{~K} / \mathrm{L}$ & 10.7 & $\begin{array}{c}0.0096 \\
(0.0338)\end{array}$ & . \\
\hline$\left(\text { Capital Intensity, } H^{*} K / L\right)^{2}$ & 9.4 & $\begin{array}{c}0.0004 \\
(0.0017)\end{array}$ & . \\
\hline Education $_{t-3}$ & 6.0 & $\begin{array}{c}0.0039 \\
(0.0215)\end{array}$ & . \\
\hline Helsinki & 4.2 & $\begin{array}{l}-0.0058 \\
(0.0456)\end{array}$ & . \\
\hline Year & 3.4 & $\begin{array}{l}-0.0001 \\
(0.0014)\end{array}$ & . \\
\hline National Population Density & 2.6 & $\begin{array}{c}0.0010 \\
(0.0516)\end{array}$ & . \\
\hline Observations & & & 623 \\
\hline $\mathrm{R}^{2}$ & & & 0.249 \\
\hline
\end{tabular}

Note: $P \neq 0$ is the posterior inclusion probability that a regressor's posterior mean is different from zero. $* * *, * * *$, indicate $90,95,99$ percent significance levels. 
Table 2

Reduced-Form BMA Results (By City)

\begin{tabular}{|c|c|c|c|}
\hline & \multicolumn{3}{|c|}{ Dependent Variable: Log median $\mathrm{SO}_{2}$ concentrations, 5-year averages } \\
\hline & $P \neq 0$ & $\begin{array}{c}\text { Posterior Mean } \\
\text { (S.D.) }\end{array}$ & $\begin{array}{c}\text { Best Model Mean } \\
\text { (S.D.) }\end{array}$ \\
\hline Intercept & 100.0 & $\begin{array}{c}15.8235 \\
(27.8085)\end{array}$ & $\begin{array}{c}-4.5770 * * * \\
(1.1233)\end{array}$ \\
\hline Trade & 96.5 & $\begin{array}{l}-2.1790 \\
(0.8050)\end{array}$ & $\begin{array}{c}-2.5691 * * * \\
(0.7329)\end{array}$ \\
\hline Executive Constraints & 92.5 & $\begin{array}{l}-0.1626 \\
(0.0691)\end{array}$ & $\begin{array}{c}-0.1916^{* * * *} \\
(0.0601)\end{array}$ \\
\hline Precipitation Variation & 92.0 & $\begin{array}{l}42.6770 \\
(18.5787)\end{array}$ & $\begin{array}{c}51.0975^{* * *} \\
(15.1028)\end{array}$ \\
\hline$\left(G P_{t-3}\right)^{2}$ & 81.4 & $\begin{array}{l}-2.8631 \\
(2.1788)\end{array}$ & $\begin{array}{c}-3.8403 * * * \\
(1.2763)\end{array}$ \\
\hline$\left(G_{t-3}\right)^{3}$ & 81.0 & $\begin{array}{c}0.5922 \\
(0.4306)\end{array}$ & $\begin{array}{c}0.7824 * * * \\
(0.2412)\end{array}$ \\
\hline GDP $_{t-3}$ & 66.2 & $\begin{array}{c}3.5128 \\
(3.3483)\end{array}$ & $\begin{array}{l}4.9447 * * \\
(2.2508)\end{array}$ \\
\hline Year & 40.9 & $\begin{array}{l}-0.0102 \\
(0.0144)\end{array}$ & . \\
\hline Education $_{t-3}$ & 19.6 & $\begin{array}{c}0.0318 \\
(0.0771)\end{array}$ & . \\
\hline Investment & 19.3 & $\begin{array}{l}-0.0038 \\
(0.0092)\end{array}$ & . \\
\hline Helsinki & 10.9 & $\begin{array}{c}0.0306 \\
(0.1114)\end{array}$ & . \\
\hline$(G D P)^{2}$ & 7.3 & $\begin{array}{c}0.0317 \\
(0.9982)\end{array}$ & . \\
\hline$(G D P)^{3}$ & 6.9 & $\begin{array}{l}-0.0049 \\
(0.1987)\end{array}$ & . \\
\hline GDP & 6.7 & $\begin{array}{l}-0.0526 \\
(1.4550)\end{array}$ & . \\
\hline Capital Intensity, $H^{*} \mathrm{~K} / \mathrm{L}$ & 6.2 & $\begin{array}{c}0.0041 \\
(0.0328)\end{array}$ & . \\
\hline$\left(\text { Capital Intensity, } H^{*} K / L\right)^{2}$ & 5.0 & $\begin{array}{l}-0.0001 \\
(0.0013)\end{array}$ & . \\
\hline Temperature & 3.7 & $\begin{array}{l}-0.0013 \\
(0.0167)\end{array}$ & . \\
\hline National Population Density & 3.3 & $\begin{array}{c}0.0027 \\
(0.1190)\end{array}$ & . \\
\hline Observations & & & 263 \\
\hline $\mathrm{R}^{2}$ & & & 0.319 \\
\hline
\end{tabular}

Note: $P \neq 0$ is the posterior inclusion probability that a regressor's posterior mean is different from zero. $* * *, * * *$, indicate $90,95,99$ percent significance levels. 
Table 3

\section{Reduced-Form BMA Results (By Country)}

\begin{tabular}{|c|c|c|c|}
\hline & \multicolumn{3}{|c|}{ Dependent Variable: Log median SO2 concentrations, 5-year averages } \\
\hline & $\mathbf{P} \neq \mathbf{0}$ & Posterior Mean & Best Model Mean \\
\hline Intercept & 100.0 & $\begin{array}{c}68.7436 \\
(37.1783)\end{array}$ & $\begin{array}{c}87.6426^{* * *} \\
(28.8034)\end{array}$ \\
\hline Executive Constraints & 99.9 & $\begin{array}{l}-0.2090 \\
(0.0503)\end{array}$ & $\begin{array}{c}-0.1977 * * * \\
(0.0585)\end{array}$ \\
\hline Precipitation Variation & 99.8 & $\begin{array}{c}59.4164 \\
(14.9510)\end{array}$ & $\begin{array}{c}59.0806 * * * \\
(17.5418)\end{array}$ \\
\hline Temperature & 98.4 & $\begin{array}{l}-0.3317 \\
(0.1022)\end{array}$ & $\begin{array}{c}-0.3732 * * * \\
(0.1010)\end{array}$ \\
\hline Trade & 96.9 & $\begin{array}{l}-1.7149 \\
(0.6302)\end{array}$ & $\begin{array}{c}-1.6653 * * * \\
(0.6428)\end{array}$ \\
\hline Education $_{t-3}$ & 96.0 & $\begin{array}{c}0.4405 \\
(0.1659)\end{array}$ & $\begin{array}{c}0.4757^{* * *} \\
(0.1499)\end{array}$ \\
\hline Year & 86.7 & $\begin{array}{l}-0.0352 \\
(0.0190)\end{array}$ & $\begin{array}{c}-0.0446^{* * * *} \\
(0.0149)\end{array}$ \\
\hline$\left(\operatorname{GDP}_{t-3}\right)^{2}$ & 32.8 & $\begin{array}{l}-0.2129 \\
(0.6308)\end{array}$ & . \\
\hline$\left(\operatorname{GDP}_{t-3}\right)^{3}$ & 18.3 & $\begin{array}{c}0.0159 \\
(0.1381)\end{array}$ & . \\
\hline $\operatorname{GDP}_{t-3}$ & 14.0 & $\begin{array}{l}-0.0003 \\
(0.7992)\end{array}$ & . \\
\hline GDP & 13.7 & $\begin{array}{c}0.1433 \\
(0.6564)\end{array}$ & . \\
\hline Helsinki & 12.2 & $\begin{array}{l}-0.0370 \\
(0.1389)\end{array}$ & . \\
\hline$(G D P)^{2}$ & 10.9 & $\begin{array}{c}0.0122 \\
(0.2817)\end{array}$ & . \\
\hline$(G D P)^{3}$ & 10.7 & $\begin{array}{c}0.0046 \\
(0.0724)\end{array}$ & . \\
\hline Investment & 6.4 & $\begin{array}{l}-0.0006 \\
(0.0039)\end{array}$ & . \\
\hline National Population Density & 5.7 & $\begin{array}{c}0.0207 \\
(0.1726)\end{array}$ & . \\
\hline Capital Intensity, $H^{*} K / L$ & 5.4 & $\begin{array}{c}0.0005 \\
(0.0172)\end{array}$ & . \\
\hline$\left(\text { Capital Intensity, } H^{*} K / L\right)^{2}$ & 5.2 & $\begin{array}{l}-0.0001 \\
(0.0008)\end{array}$ & . \\
\hline Observations & & & 109 \\
\hline $\mathrm{R}^{2}$ & & & 0.475 \\
\hline
\end{tabular}

Note: $P \neq 0$ is the posterior inclusion probability that a regressor's posterior mean is different from zero. ${ }^{*}, * * * * *$, indicate $90,95,99$ percent significance levels. 
Table 4 - Structural BMA Results

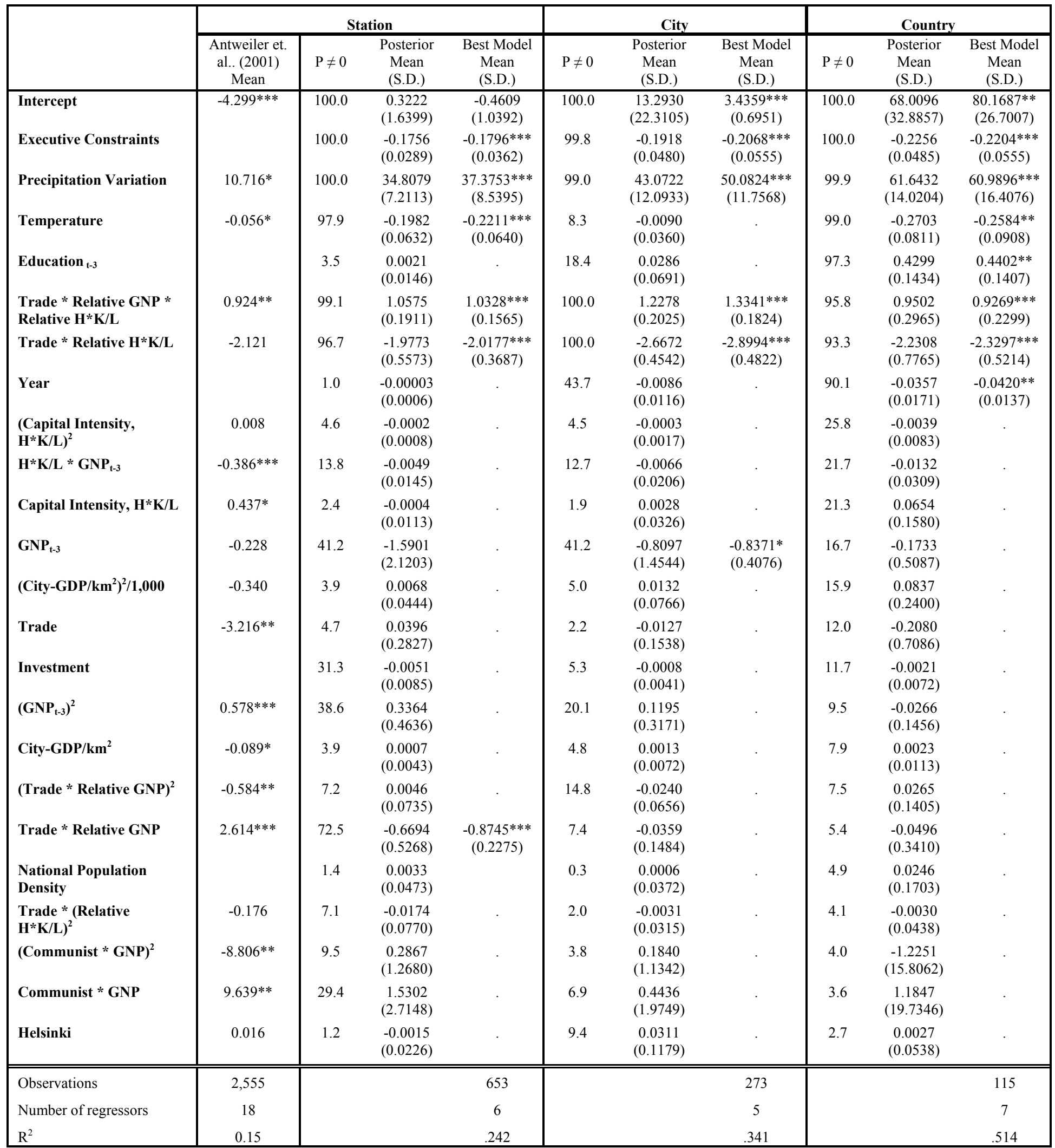

Note: $P \neq 0$ is the posterior inclusion probability that a regressor's posterior mean is different from zero. ***, ***, indicate $95,99,99.9$ percent significance levels. Antweiler et al. (2001) do not report standard errors 